\title{
Penggunaan lensa kontak dan pengaruhnya terhadap dry eyes pada mahasiswa Fakultas Ekonomi Universitas Sam Ratulangi
}

\author{
${ }^{1}$ Eunike L. Pietersz \\ ${ }^{2}$ Vera Sumual \\ ${ }^{2}$ Laya Rares
}

\author{
${ }^{1}$ Kandidat Skripsi Fakultas Kedokteran Universitas Sam Ratulangi Manado \\ ${ }^{2}$ Bagian Ilmu Kesehatan Mata Fakultas Kedokteran Universitas Sam Ratulangi Manado \\ Email: ipietersz11_204@ymail.com
}

\begin{abstract}
Eye is the most vital organ of sight to detect light. Many factors can cause eye disorders, one of them is dry eyes. The causes of dry eyes are: age, sex/gender, contact lens usage, smoking, and air conditioned room. This study aimed to determine the effect of contact lens to dry eyes. This was an observational study with a cross sectional design. Samples were students of Faculty of Economics University of Sam Ratulangi batch 2011-2014. There were 30 respondents who used contact lenses obtained by random sampling. The results showed that there were 28 female respondents and 2 male respondents aged 18- 21 years old. Most of them used contact lenses due to aesthetic reason rather than to substitution of eye glasses. The most common type of contact lens was Rigid Gas Permeable (RGP). Of the 30 respondents, there were 16 students (53.3\%) who suffered from dry eyes. The statistical analysis showed a correlation coefficient ( $\mathrm{r}$ ) -0.0612 and a p value $0.000<\alpha=0,05$. Conclusion: There was a strong correlation between using of contact lens and its influence on the eyes (dry eyes) among students of Faculty of Economics University of Sam Ratulangi.
\end{abstract}

Keywords: contact lenses, dry eyes

\begin{abstract}
Abstrak: Mata adalah organ penglihatan yang paling vital untuk mendeteksi cahaya. Banyak faktor yang menyebabkan gangguan pada mata, salah satunya ialah dry eyes (mata kering). Penyebab dry eyes ialah antara lain: usia, jenis kelamin, penggunaan lensa kontak, merokok, dan ruang ber-AC. Penelitian ini bertujuan untuk mengetahui pengaruh penggunaan lensa kontak terhadap dry eyes. Jenis penelitian ini observasional dengan desain potong lintang. Responden ialah mahasiswa/i Fakultas Ekonomi Universitas Sam Ratulangi angkatan 20112014 yang menggunakan lensa kontak dan diambil secara random. Hasil penelitian memperlihatkan dari 30 responden pengguna lensa kontak terdapat 28 responden perempuan dan 2 responden laki-laki dengan usia 18 tahun sampai 21 tahun. Alasan penggunaan lensa kontak terbanyak sebagai estetika dan bukan sebagai pengganti kacamata. Jenis kontak lensa yang tersering digunakan ialah Rigid Gas Permeable (RGP). Berdasarkan distribusi frekuensi terlihat bahwa terdapat responden dengan dry eyes sebanyak 16 orang (53,3\%). Hasil uji statistik mendapatkan nilai koefisien korelasi (r) sebesar $-0,0612$ dan nilai $p=0,000<\alpha 0,05$. Simpulan: Terdapat hubungan yang kuat penggunaan lensa kontak dan pengaruhnya terhadap dry eyes pada mahasiswa Fakultas Ekonomi Universitas Sam Ratulangi.
\end{abstract}

Kata kunci: lensa kontak, dry eyes

Mata merupakan indra terpenting dalam kehidupan manusia, tanpa mata manusia tidak dapat melakukan aktivitas sehari-hari dengan baik. Mata adalah organ penglihatan yang paling vital untuk mendeteksi cahaya. ${ }^{1}$ Fungsi mata yang paling sederhana yaitu mengetahui apakah lingkungan sekitarnya terang atau gelap. ${ }^{1}$ 
Mata merupakan alat vital yang sangat peka terhadap semua hal bahkan yang terkecil yang dapat menyebabkan gangguan pada mata. Banyak faktor yang menyebabkan gangguan pada mata, salah satunya ialah dry eyes (mata kering). Mata kering adalah suatu keadaan berkurangnya fungsi air mata yang ditandai oleh hiperemia konjungtiva, penebalan mata dan epitel kornea, rasa gatal, rasa terbakar pada mata, dan sering disertai penurunan penglihatan. $^{2}$

Penelitian yang dilakukan oleh Schaumberg (2003) melaporkan bahwa prevalensi dry eyes pada populasi di Amerika Serikat yang berumur $\geq 50$ tahun yaitu perempuan sebanyak 7,8\% (sekitar 3,2 juta) dan laki-laki sebanyak 4,7\% (sekitar 1,6 juta). ${ }^{3}$ Senada dengan hasil tersebut, Beaver Dam Eye Study melaporkan terdapat $14,4 \%$ populasi dengan keluhan dry eyes dan 99\% diantaranya orang berkulit putih. Penelitian oleh Melbourne study di Australia melaporkan prevalensi sekitar 7,4\% di antara populasi dengan rata-rata umur 59 tahun. ${ }^{4}$ Di Makassar sendiri, kasus dry eyes lebih banyak ditemukan pada wanita dengan perbandingan wanita:laki-laki sekitar $2: 1 .^{5}$

Penyakit dry eyes adalah suatu penyakit mata yang sering ditemui (25\% dari semua penyakit mata dengan penyebab multifaktorial yang menyebabkan kelainan air mata dan permukaan mata sehingga terjadi ketidaknyamanan, gangguan visual, dan ketidakstabilan film air mata yang berpotensi merusak permukaan mata. Hal ini disertai dengan peningkatan osmolaritas film air mata dan radang pada permukaan mata. ${ }^{6}$ Beberapa faktor yang menyebabkan dry eyes (mata kering) ialah: usia, jenis kelamin, penggunaan lensa kontak, merokok, ruang ber-AC. ${ }^{8}$

Dari beberapa penelitian ditemukan sekitar 43-50\% penggunaan lensa kontak mengalami mata kering (Begley dkk., 2000). Tutt (2000) menunjukan adanya penurunan kualitas bayangan retina pada penggunaan lensa kontak. $^{8}$

Lensa kontak sudah menjadi bagian gaya hidup masyarakat modern masa kini. Lensa kontak sangat terkenal terutama dikota-kota besar. ${ }^{9}$ Banyak orang terutama kaum wanita menggunakan lensa kontak bukan sekedar alat bantu penglihatan (kacamata) tetapi juga dipakai sebagai alat kosmetika untuk mempercantik bagian mata dengan berbagai warna yang menarik.

\section{METODE PENELITIAN}

Jenis penelitian ini ialah observasional dengan desain potong lintang. Penelitian ini dilaksanakan pada ruang kuliah di Fakultas Ekonomi Universitas Sam Ratulangi yang berlangsung selama 2 bulan sejak bulan November - Desember 2014. Populasi target dalam penelitian ini ialah mahasiswa Fakultas Ekonomi angkatan 2011-2014 di Universitas Sam Ratulangi yang menggunakan lensa kontak dan sampel penelitian berjumlah 30 mahasiswa yang di ambil secara sampling random.

\section{HASIL PENELITIAN}

Tabel 1. Karakteristik Responden

\begin{tabular}{llll}
\hline & & $\mathrm{N}$ & $\%$ \\
\hline \multirow{3}{*}{$\begin{array}{l}\text { Jenis } \\
\text { Kelamin }\end{array}$} & Laki-laki & 2 & 6,7 \\
\cline { 2 - 4 } & Perempuan & 28 & 93,3 \\
\cline { 2 - 4 } & Total & 30 & 100 \\
\hline \multirow{4}{*}{ Umur } & 18 tahun & 3 & 10 \\
\cline { 2 - 4 } & 19 tahun & 13 & 43,3 \\
\cline { 2 - 4 } & 20 tahun & 10 & 33,3 \\
\cline { 2 - 4 } & 21 tahun & 3 & 10 \\
\cline { 2 - 4 } & 22 tahun & 1 & 3,3 \\
\cline { 2 - 4 } & Total & 30 & 100 \\
\hline \multirow{4}{*}{ Angkatan } & 2011 & 3 & 10 \\
\cline { 2 - 4 } & 2012 & 14 & 46,7 \\
\cline { 2 - 4 } & 2013 & 10 & 33,3 \\
\cline { 2 - 4 } & 2014 & 3 & 10 \\
\hline \multirow{3}{*}{ Jurusan } & Total & 30 & 100 \\
\cline { 2 - 4 } & Akutansi & 15 & 50 \\
\cline { 2 - 4 } & IBA & 1 & 3,3 \\
\cline { 2 - 4 } & Manajemen & 14 & 46,7 \\
\hline & Total & 30 & 100 \\
\hline
\end{tabular}

Hasil penelitian yang dilakukan pada bulan November sampai Desember 2014 mendapatkan bahwa sebagian besar responden ialah: berjenis kelamin 
perempuan sebanyak 28 responden (93,3\%); kategori usia 19 tahun sebanyak 13 responden (43,3\%); termasuk pada angkatan 2012 sebanyak 14 responen
(46,7\%) dengan jurusan terbanyak berasal jurusan akutansi dengan jumlah 15 responden (50\%) (Tabel 1).

Tabel 2. Analisis Menurut Item Pertanyaan

\begin{tabular}{|c|c|c|c|}
\hline Pertanyaan & Jawaban & $\mathrm{N}$ & $\%$ \\
\hline \multirow{3}{*}{$\begin{array}{l}\text { Penurunan } \\
\text { Ketajaman }\end{array}$} & $\mathrm{Ya}$ & 19 & 63,3 \\
\hline & Tidak & 11 & 36,7 \\
\hline & Total & 30 & 100 \\
\hline \multirow{4}{*}{ Jenis Kacamata } & Minus & 12 & 40 \\
\hline & Cylindris & 1 & 3,3 \\
\hline & Lainnya & 17 & 56,7 \\
\hline & Total & 30 & 100 \\
\hline \multirow{5}{*}{$\begin{array}{c}\text { Asal Tahu } \\
\text { Lensa Kontak }\end{array}$} & Dokter & 4 & 13,3 \\
\hline & Media & 7 & 23,3 \\
\hline & Orang lain & 18 & 60 \\
\hline & Lainnya & 1 & 3,3 \\
\hline & Total & 30 & 100 \\
\hline \multirow{3}{*}{$\begin{array}{c}\text { Alasan } \\
\text { Menggunakan }\end{array}$} & Pengganti Kacamata & 9 & 30 \\
\hline & Fashion & 21 & 70 \\
\hline & Total & 30 & 100 \\
\hline \multirow{5}{*}{$\begin{array}{l}\text { Tempat Membeli } \\
\text { Lensa Kontak }\end{array}$} & Optik & 23 & 76,7 \\
\hline & Dokter & 1 & 3,3 \\
\hline & Online & 3 & 10 \\
\hline & Lainnya & 3 & 10 \\
\hline & Total & 30 & 100 \\
\hline \multirow{3}{*}{ Jenis Pemakaian } & Daily Wear & 25 & 83,3 \\
\hline & Continous Wear & 5 & 16,7 \\
\hline & Total & 30 & 100 \\
\hline \multirow{4}{*}{ Masa Pakai } & Disposible & 5 & 16,7 \\
\hline & Planning R. Program & 11 & 36,7 \\
\hline & RGP & 14 & 46,7 \\
\hline & Total & 30 & 100 \\
\hline \multirow{3}{*}{$\begin{array}{c}\text { Waktu } \\
\text { Menggunakan }\end{array}$} & Terus-menerus & 5 & 16,7 \\
\hline & Ada Jeda & 25 & 83,3 \\
\hline & Total & 30 & 100 \\
\hline \multirow{6}{*}{$\begin{array}{c}\text { Lama } \\
\text { Menggunakan }\end{array}$} & $<3$ bulan & 4 & 13,3 \\
\hline & 6 bulan & 2 & 6,7 \\
\hline & 1 tahun & 8 & 26,7 \\
\hline & $>1$ tahun & 15 & 50 \\
\hline & Lainnya & 1 & 3,3 \\
\hline & Total & 30 & 100 \\
\hline \multirow{3}{*}{ Berobat ke Dokter } & $\mathrm{Ya}$ & 6 & 20 \\
\hline & Tidak & 24 & 80 \\
\hline & Total & 20 & 100 \\
\hline \multirow{5}{*}{$\begin{array}{c}\text { Kadar } \\
\text { Air Mata }\end{array}$} & $2 \mathrm{ml}$ & 2 & 6,7 \\
\hline & $4 \mathrm{ml}$ & 2 & 6,7 \\
\hline & $5 \mathrm{ml}$ & 1 & 3,3 \\
\hline & $9 \mathrm{ml}$ & 2 & 6,7 \\
\hline & $10 \mathrm{ml}$ & 1 & 3,3 \\
\hline
\end{tabular}


Pietersz, Sumual, Rares: Penggunaan lensa kontak...

\begin{tabular}{cccc}
\hline Pertanyaan & Jawaban & N & $\%$ \\
\hline $13 \mathrm{ml}$ & 1 & 3,3 \\
\cline { 2 - 4 } & $14 \mathrm{ml}$ & 1 & 3,3 \\
\cline { 2 - 4 } & $15 \mathrm{ml}$ & 1 & 3,3 \\
\cline { 2 - 4 } & $16 \mathrm{ml}$ & 1 & 3,3 \\
\hline $19 \mathrm{ml}$ & 2 & 6,7 \\
\hline $21 \mathrm{ml}$ & 1 & 3,3 \\
\hline $24 \mathrm{ml}$ & 1 & 3,3 \\
\hline $25 \mathrm{ml}$ & 1 & 3,3 \\
\hline $26 \mathrm{ml}$ & 1 & 3,3 \\
\hline $27 \mathrm{ml}$ & 1 & 3,3 \\
\hline $30 \mathrm{ml}$ & 1 & 3,3 \\
\hline $32 \mathrm{ml}$ & 2 & 6,7 \\
\hline $33 \mathrm{ml}$ & 1 & 3,3 \\
\hline $34 \mathrm{ml}$ & 1 & 3,3 \\
\hline $35 \mathrm{ml}$ & 2 & 6,7 \\
\hline & $35 \mathrm{ml}$ & 4 & 13,3 \\
\hline & Total & 30 & 100 \\
\hline
\end{tabular}

Berdasarkan distribusi frekuensi terlihat bahwa penderita dry eyes sebanyak 16 orang (53,3\%) dan yang bukan dry eyes 14 orang (46,7\%) (Tabel 3).

Tabel 3. Distribusi Frekuensi Penderita Dry Eyes

\begin{tabular}{lcc}
\hline \multicolumn{1}{c}{ Karakterisitk } & F (orang) & $\%$ \\
& & \\
\hline Penderita Dry Eyes & & \\
Ya & 16 & 53,3 \\
Tidak & 14 & 46,77 \\
\hline Total & 30 & 100 \\
\hline
\end{tabular}

\section{BAHASAN}

Penelitian ini dilakukan pada mahasiswa Fakultas Ekonomi di Universitas Sam Ratulangi dengan jumlah 30 responden yang sebagian besar terdiri dari responden perempuan. Secara global, pada tahun 2010 pengguna lensa kontak dua pertiga ialah perempuan. ${ }^{8}$ Pada tahun 2004, diketahui penggunaan lensa kontak di Amerika sekitar 38 juta orang, dan ratarata pengguna lensa kontak diseluruh dunia sekitar 128 juta orang, dan sekitar 13,2 juta orang berusia antara 18 sampai 34 tahun. $^{9}$ Pada penelitian yang didapatkan di Fakultas Ekonomi rentang umur pengguna lensa kontak antara 18 sampai 22 tahun.

Dari hasil penelitian yang dilakukan terlihat bahwa sebagian besar 19 responden (63,3\%) mengalami penurunan ketajaman penglihatan. Hal ini mungkin disebabkan oleh aktifitas mahasiswa yang kesehariannya sering menggunakan komputer atau laptop dalam membantu tugasnya sebagai mahasiswa

Penelitian yang dilakukan pada mahasiswa Ekonomi yang alasan penggunaan lensa kontak hanya untuk estetika yang berjumlah 21 responen (70\%) dari 30 responden sedangkan yang menggunakan lensa kontak sebagai pengganti kacamata hanya 9 responden (30\%).

Pada penelitian yang dilakukan pada mahasiswa Fakultas Ekonomi didapatkan bahwa jenis pemakaian yang terbanyak yaitu daily-wear dengan jumlah 25 responden (83,3\%) dan masa pakai terbanyak yaitu Rigid Gas Permeable (RGP) dengan jumlah 14 responden (46,7\%). Daily wear soft lens terbuat dari plastik lembut dan fleksibel, yang mempermudah masuknya oksigen ke mata. Waktu adaptasi yang sangat pendek, lebih nyaman dan tidak mudah terlepas seperti lensa kontak yang lain, tersedia dalam berbagai warna dan bifokal serta baik untuk selalu menjaga penampilan. ${ }^{10}$ Dengan beragam keuntungan dalam pemakaian daily wear soft lens menyebabkan banyak 
mahasiswa di Fakultas Ekonomi Universitas Sam Ratulangi memilih untuk menggunakannya.

Hasil uji statistik mendapatkan nilai koefisien korelasi (r) sebesar -0,0612 dan nilai $\mathrm{p}=0,000<\alpha 0,05$. Hal ini menunjukkan antara adanya pengaruh yang "kuat” antara penggunaan lensa kontak dan dry eyes. Tanda negatif menunjukkan bahwa saat variabel $\mathrm{X}$ (lensa kontak) meningkat, maka variabel Y (dry eyes) menurun. Begitu juga sebaliknya bila variabel X (lensa kontak) menurun, maka variabel Y (dry eyes) meningkat.

\section{SIMPULAN}

Berdasarkan hasil penelitian pada mahasiswa Fakultas Ekonomi Universitas Sam Ratulangi Manado dapat disimpulkan bahwa sebagian besar kelompok pemakai lensa kontak berjenis kelamin perempuan, dengan kisaran usia 18-22 tahun. Terdapat hubungan bermakna antara penggunaan lensa kontak dan pengaruhnya terhadap dry eyes

\section{SARAN}

1. Pengguna lensa kontak harus berkonsultasi terlebih dahulu kepada dokter yang berkompetensi untuk menggetahui cara penggunaan dan menyimpanan lensa kontak yang benar.

2. Menjaga kebersihan lensa kontak

3. Mengurangi waktu penggunaan lensa kontak jika tidak diperlukan, seperti melepaskan lensa kontak pada saat tidur, mandi, berenang.

4. Segera lakukan pemeriksaan ke dokter, bilamana didapatkan gejala yang berkelanjutan.

5. Bagi yang ingin menjadikan penelitian ini sebagai bahan acuan untuk penelitian selanjutnya agar melakukan prosedur pemeriksaan visus terlebih dahulu sebelum melakukan pemeriksaan Schimer Test.

6. Juga disarankan untuk memberikan penyuluhan kepada mahasiswa
Universitas Sam Ratulangi dan kepada masyarakat luas mengenai penggunaan lensa kontak.

\section{DAFTAR PUSTAKA}

1. Anggreani Z. Hubungan Dry Eyes Syndrome dengan Menopause. Manado: Fakultas Kedokteran Universitas Sam Ratulangi; 2013

2. Ilyas, Sidarta, Yulianty, Sri Rahayu. Ilmu penyakit mata (4th ed). Jakarta. Penerbit FK-UI, 2010; p. 142.

3. Schaumberg DA, Sullivan DA, Buring JE, Dana MR. Prevalence of dry eye syndrome among US women. Am J Opthalmologhy 2003;136:318-26.

4. Abelson MB, Rosner R. Epidemiologic studies of dry eye in dry eye and ocular surface disorders. Suresh K. Pandey, editor. New Delhi: Jaypee Brother Medical Publisher, 2001; p. 3-9.

5. Syawal SR. Suatu Cakrawala Baru Mengenai Patogenesis dari Penanganan Sindrom "Dry Eye". Jurnal Medika Nusantara Suplement. 2005;26:84-7.

6. Sitompul R, Nora RLD. Glaukoma dan Penyakit Mata Kering Serta Peran Pengawet Dalam Obat Glaukoma. Jakarta: J Opthalmologhy FKUI, 2014.

7. Wijana N. Ilmu Penyakit Mata (Cetakan ke5). Jakarta, 1989.

8. Muralidran T. Tingkat Pengetahuan Pemakaian Lensa Kontak dalam Kalangan Mahasiswa FK USU Stambuk 2009 dan 2011. Medan: J Kedokteran, 2013.

9. Rahmad, Aryani AA. Tingkat Pengetahuan Pengguna Lensa Kontak Terhadap Dampak Negatif Penggunaannya pada Pelajar SMA YPSA. J FK USU. 2013;1(1): 1-3.

10. Science Daily, Reports Characterize Fungal Eye Infections Among Soft Contact Lens Wearers. [cited 09 May 2016]. Available from: URL: https://www.sciencedaily.com/release s/2006/06/060613082800.htm. 